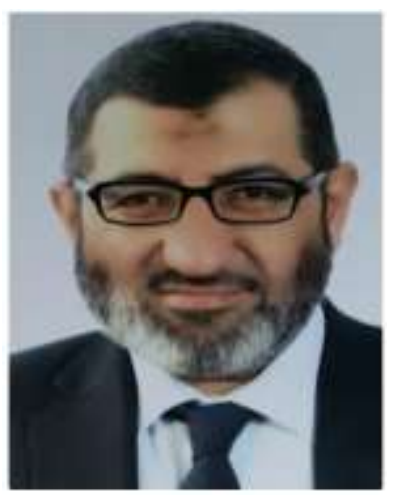

\title{
How the HBRC contributes to the Sustainability in Egypt
}

\author{
Prof. Khalid Mohamed El Zahaby \\ Chairman of the Housing \& Building National \\ Research Center, HBRC \\ Cairo, EGYPT \\ Email:kmelzaha99@yahoo.com
}

Housing \& Building National Research Center, HBRC, is a governmental institute subordinate to the Ministry of Housing, Utilities and Urban Communities which started in 1954 by 12 employees. HBRC now has more than 1100 employees, 300 of which are M.Sc., and/or Ph.D. holders.

HBRC is the sole entity nationwide responsible for issuing the Egyptian Codes (30) as well as technical specifications (21), in addition to providing periodical training for these codes and specifications. Training also extends to a variety of engineering subjects and it serves both public and private sectors.

HBRC is involved in several national scientific research plans as well as researches leading to academic degrees.

One of the main activities of HBRC is serving the community through the assessment of mal-functioning structures nationwide, as well as technically refereeing disputes between different parties. Moreover, HBRC is taking a substantial role in the quality control and construction supervision of the national projects.

It is worth mentioning that all HBRC labs are ISO 17025 accredited by the International Accreditation Services, IAS.

Moreover, HBRC hosts the Egyptian Green Building Council, originated back in 2009 by a ministerial decree. Several rating systems exist worldwide, e.g., LEED, BREEAM, CASBEE, etc. In this capacity, a rating system for new buildings, termed Green Pyramid Rating System (GPRS) has been developed. It has been issued back in December 2010. Other rating systems have followed since then, including GPRS for banks, communities, etc. These rating systems have been applied to several structures / compounds, e.g., the first governmental green building has been designed at HBRC; compounds, club houses and banks have been assessed according to the appropriate GPRS.

HBRC has carried out some tangible steps towards the application of the green building concept in Egypt. The use of traditional construction systems has to be developed so as to coop with the green building concepts. This started back in 2010 when a research team from HBRC visited several countries so as to carry out smooth technology transfer after making the necessary adaptations for the used systems in order to suit the Egyptian climate, habits, etc. A sustainable park subordinate to HBRC has been initiated at the city of 6 October in which full scale models have been constructed with non-traditional systems and/or materials of construction. This can be summarized briefly as follows:

- $\quad$ Sandwich panel system in which polystyrene panels are used with wire mesh attached to both sides and covered with shotcrete. This is used for both walls and ceiling.

Glass reinforced concrete panels (GRC) are also used for both walls and ceiling. 
- $\quad$ Cold formed steel is used for both walls and ceiling.

- Sand sacs, in which sacs are filled with sand or silty sand and stacked together to form the walls of the structure. Ceilings can also be built in the same manner with special technique in construction.

- Rammed earth in which soil is mixed with a very low percentage of cement (about 4 to $5 \%$ ) and the mixture is manually rammed with a hammer to build the walls of the structure.

Alternatively, the mixture can be used to form blocks with different shapes using a hand operated simple machine which produces several blocks at a time. The blocks are then sprayed with water and treated for 28 days, after which these blocks can be used to construct both the walls and ceiling of the structure. A full scale model is built as such at the premises of the headquarters of HBRC at Dokki.

All the previously shown methods of construction have a common factor which is that they are all eco buildings, i.e., environmentally friendly structures which help minimize their life time running cost, help in the reduction of harmful emissions, thus supporting the environment, etc. In short, these types of systems can be considered among the future systems to be used rather than the traditional methods which are becoming more expensive and more important some of the constituents of the conventional methods are getting depleted.

Part of the vision of HBRC is to help create a green environment.

\section{About Prof. Khalid Mohamed El Zahaby}

Prof. El Zahaby is currently the Chairman of the Housing \& Building National Research Center (HBRC) subordinate to the Ministry of Housing, Utilities \& Urban Communities. He is also the chairman of the Metropolis ${ }^{\circledR}$ regional branch as well the Chairman of Urban Training institute (UTI). He is the Vice-Chairman of the Egyptian Green Building council. He started as a research assistant and progressed to be a professor of geotechnical engineering then Vice Chairman of HBRC before being nominated for the post of the Chairman. He obtained his B.Sc. and M.Sc. from Cairo University, Egypt and his Ph.D. from North Carolina State University, USA.

He authored and co-authored 36 research papers published in national and international journals and/or conferences. He chaired several international conferences and presented invited keynote lectures in several countries. Moreover, Prof. El Zahaby supervised tens of theses and refereed tens of M.Sc, Ph.D. and scientific papers. He is also a member on several regional and international organizations.

In his capacity as a researcher at HBRC or being a geotechnical consultant, Prof. El Zahaby prepared more than 2000 geotechnical studies in Egypt and some Arab countries including geotechnical reports, side supporting systems, dewatering, etc.

It is worth mentioning that Prof. El Zahaby is a member on several standing committees as well as a variety of Code committees.

Prof. El Zahaby is the recipient of several awards, among which are the ICC Global Award, USA, 2013; the award given by His Highness, Prince Mansur Ibn Metaab, KSA, 2013. 